\title{
Functional Anatomy of a Prelearned Sequence of Horizontal Saccades in Humans
}

\author{
Laurent Petit, ${ }^{1,2}$ Christophe Orssaud, ${ }^{1,2}$ Nathalie Tzourio, ${ }^{1}$ Fabrice Crivello, ${ }^{1}$ Alain Berthoz, ${ }^{2}$ and \\ Bernard Mazoyer ${ }^{1}$ \\ 1 Groupe d'Imagerie Neurofonctionnelle, Service Hospitalier Frédéric Joliot, 91406 Orsay Cedex, France, and EA 1555, \\ Université Paris 7, Paris, France, and 'Laboratoire de Physiologie de la Perception et de l'Action, Centre National de la \\ Recherche Scientifique-Collège de France, 75270 Paris Cedex 06, France
}

We have used positron emission tomography (PET) to study the functional anatomy of the repetition of a prelearned sequence of horizontal saccadic eye movements. Five subjects had to memorize a sequence of six successive horizontal saccades. The subjects were scanned in total darkness under three different conditions: at rest, during the execution of self-paced horizontal saccades, and while repeating a prelearned saccades sequence. The repetition of the prelearned saccades sequence led to specific normalized regional cerebral blood flow (NrCBF) increases at the depth of the superior frontal sulcus as well as at the rostral part of the supplementary motor area, whereas at the parietal level an important activation was observed in the intraparietal sulcus extending up to the precuneus. In addition, it was noticed that compared with the resting control condition, both oculomotor tasks activated a common set of cortical and subcortical areas. At the cortical level, this

Visual processing in the cerebral cortex proceeds through multiple visual areas into a dorsal pathway responsible for spatial vision and into a ventral pathway responsible for object vision (for review, see Ungerleider and Haxby, 1994). How information coming from the various cortical areas is combined to generate perception and action remains unclear. According to Fuster (1995), the neural process of transition from perception to action may be relatively simple if both perception and action are simple and if the first leads directly to the second. If behavior contains contingencies between perception and actions that are separate in time, then the processing must include mechanisms to mediate these contingencies. Thus, the cortex must have the means to translate perception into action across time. It must represent a long and perhaps imprecise sequence of behavior, and it must monitor the sequence during its execution.

Ihe investigation of visually guided saccadic eye movements offers an opportunity to examine this issue, because information

Received Jan. 25, 1996; revised March 20, 1996; accepted March 27, 1996.

This work was supported by a grant from the Ministère de la Recherche et de la Technologie, Action "Sciences de la Cognition" (91.C.0019). We are deeply indebted to the Orsay radiochemistry staff for labeled-water production, and we thank Laurence Laurier and Marc Joliot for their invaluable help. We also thank Isabelle Israel, who has contributed to the initial definition of the sequence of the saccades paradigm.

Correspondence should be addressed to Professeur Bernard Mazoyer, Groupe d'Imagerie Neurofonctionnelle, Service Hospitalier Frédéric Joliot, Commissariat à l’Energie Atomique-Département de Recherche Médicale, F-91401 Orsay Cedex, France.

Copyright (C) 1996 Society for Neuroscience $0270-6474 / 96 / 163714-13 \$ 05.00 / 0$ network was composed of the frontal eye fields, the supplementary eye fields, the median part of the cingulate gyrus, and the insula. At the subcortical level, the lenticular nucleus and the thalamus as well as the cerebellar vermis were activated consistently. A direct comparison of our results with those of other PET studies on spatial vision suggests that the dorsal visuospatial pathway could be extended toward the frontal premotor region. In such a scheme, visuospatial information computed in the intraparietal sulcus would be transmitted to the frontal premotor cortex to optimize a spatial-oriented behavior. This is consistent with the early proposal that perceptual and intentional components of spatial information are mediated through superior parietal and frontal areas, respectively.

Key words: saccadic eye movements; positron emission tomography; human; frontal cortex; parietal cortex; dorsal visuospatial pathway; frontal eye fields

about object identity and spatial location has to be combined to produce accurate eye movements.

Reflexive visually guided saccades triggered externally by the appearance of a peripheral visual target represent a model of a simple transition from perception to action. Several studies using positron emission tomography (PET) in healthy humans have described cortical and subcortical regions activated during the execution of reflexive visually guided saccades (Fox et al., 1985a,b; Paus et al., 1993; Anderson et al., 1994; O'Driscoll et al., 1995; Sweeney et al., 1996).

By contrast, a memory-guided saccade is triggered to drive the fovea into a memorized position where a visual target had appeared previously. Several cerebral processes are required to mediate the contingencies between perception and action to perform an accurate saccade (Pierrot-Deseilligny et al., 1995). The position of the visual target has to be encoded, remembered, and transformed into an intentional saccade vector in the retinotopic coordinate system. Previous PET studies of memory-guided saccades have focused on localizing brain structures involved in the generation of single memorized saccades (Miezin et al., 1992; Anderson et al., 1994; Nakashima et al., 1994; O'Sullivan et al., 1995; Sweeney et al., 1996). Interestingly, they have shown that the generation of such memorized saccades involved cortical and subcortical structures similar to those observed during the execution of visually guided saccades.

In a preliminary study (Berthoz et al., 1992) using the PET technique, we observed that the repetition of a prelearned sequence of horizontal saccades, as compared with the fixation of an 
imagined central point, led to specific activations in the superior parietal cortex and in the dorsolateral part of the superior frontal gyrus added to a set of cortical and subcortical regions also involved in the execution of self-paced horizontal saccades (Petit et al., 1993; Lang et al., 1994). This latter set comprised the frontal and supplementary eye fields (SEFs), the median cingulate gyrus, the lenticular nucleus, the thalamus, and the cerebellar vermis. Because continuous fixation produces activation of a frontocingulate network (Anderson et al., 1994; Petit et al., 1995), we have reconsidered our preliminary study of a prelearned sequence of horizontal saccades as compared with both a resting control condition and a self-paced saccadic task (Petit et al., 1993; Lang et al., 1994). In addition to the classical intersubject averaging approach, individual images of regional cerebral blood flow (rCBF) differences were analyzed with a detection software, Hierarchical MultiScaling Detection (HMSD), capable of detecting activation, location, and extension in single subjects (Poline and Mazoyer, 1994). This paired data analysis [statistical parametric maps (SPMs) and HMSD], using intersubject averaging and individual functional anatomy, has provided a powerful approach to the segregation of functional areas within accurate anatomical structures (Crivello et al., 1995).

\section{MATERIALS AND METHODS}

\section{Subjects}

Five right-handed healthy French male students (S1-S5), 21-27 years old, participated in this study. All were free of nervous disease or injury, and there was no abnormality on their $\mathrm{Tl}$-weighted high-resolution magnetic resonance images (MRIs). Informed written consent for each study was obtained from each subject after the procedures had been fully explained. Approval of these experiments was given by an Ethics Committee.

\section{Experimental protocol}

Using ${ }^{15}$ O-labeled water, we made six sequential PET measurements of the rCBF of each subject, replicating a series of three different experimental conditions. In the baseline control condition (Fig. 1, top; REST), instructions were to relax, to keep eyes open, and to avoid eye movements. In the first active condition (Fig. 1, middle; $S A C$ ), subjects were asked to execute self-paced voluntary horizontal saccades at both maximal amplitude and frequency, with the task started $45 \mathrm{sec}$ before the injection and pursued during the entire data acquisition period $(2 \mathrm{~min})$. This task was similar to the one we used in a previous study (Petit et al., 1993). The second active condition (Fig. 1, bottom; SEQ) consisted of the repetition of a prelearned sequence of horizontal saccades (Israël et al., 1993). In the SEQ condition, a sequence of five successive horizontal positions on an array of light-emitting diodes was presented 2 min before the ${ }^{15} \mathrm{O}$-labeled water injection. The visual target appeared first at the primary central eye position, i.e., a central fixation point, and remained there for $3 \mathrm{sec}$. The target then jumped to five consecutive different eccentric positions on the horizontal axis. The subject was requested to track the target, which stayed $2 \mathrm{sec}$ at each position. After the last position was shown, the target jumped back to the primary central position where the subject had to follow it. The target positions were allocated $5^{\circ}, 10^{\circ}$, and $15^{\circ}$ on either side of the primary central position. Each sequence presentation was repeated five times to enable the subject to memorize it. During the measurement of the normalized rCBF $(\mathrm{NrCBF})$, the subject had to repeat this sequence of six saccades as accurately as possible while trying to follow the initial rhythm of the sequence. Two different horizontal saccade sequences were used with each subject.

The tasks were performed in the following order: REST, SAC, SEQ, REST, SAC, SEQ. A black chamber was set up around the PET tomograph, the horizontal target bar, and the subject so that all PET measures were done in total darkness. The horizontal target bar was located at the back of the PET tomograph, and the subjects could see the targets with the help of a mirror placed in front of their eyes. Horizontal electrooculograms (EOG) were recorded for each subject, with external electrodes placed at the external canthi and also a right ear reference electrode, to ascertain that the requested eye movements were executed correctly (Fig. 1).

\section{REST CONDITION}

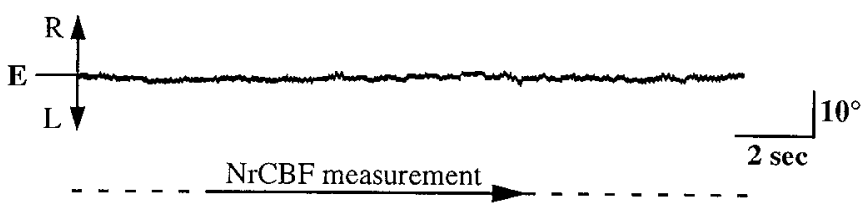

SELF-PACED SACCADES CONDITION
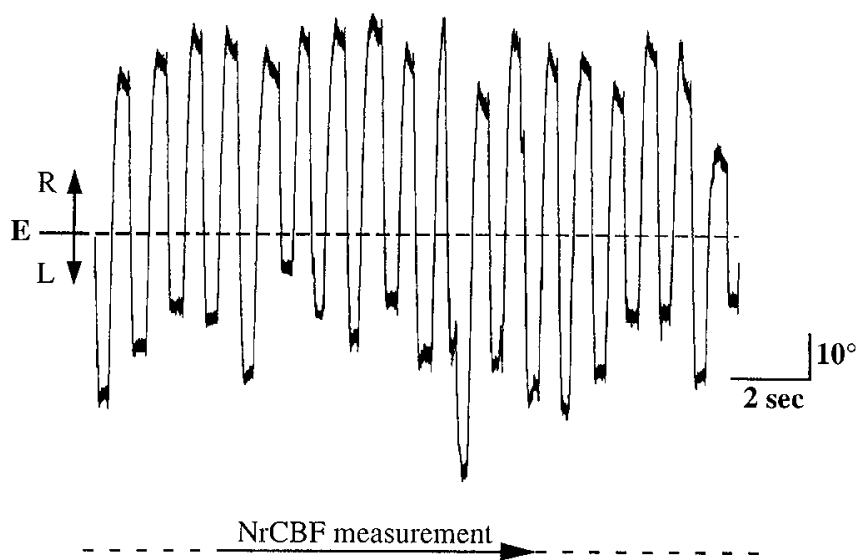

\section{PRELEARNED SACCADES SEQUENCE CONDITION}

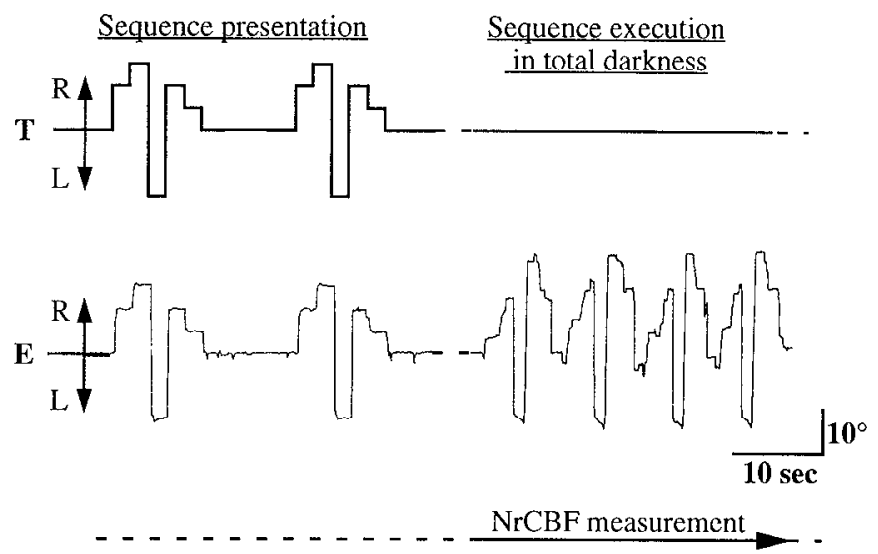

Figure 1. Sample of horizontal EOG recordings in one subject (S5) during the three conditions. $E$, Eye movements; $T$, target position along a horizontal axis; $R$, right; $L$, left.

\section{Data acquisition}

For each rCBF measurement, 31 contiguous brain slices were acquired simultaneously on an ECAT 953B/31 PET camera giving an in-plane resolution of $5 \mathrm{~mm}$ (Mazoyer et al., 1991). Emission data were acquired with septa extended. After the intravenous bolus injection of $80 \mathrm{mCi}$ of ${ }^{15} \mathrm{O}$-labeled water, a single $80 \mathrm{sec}$ scan was reconstructed (including a correction for head attenuation using a measured transmission scan) with a Hanning filter of $0.5 \mathrm{~mm}^{-1}$ and displayed with a pixel size of $1.956 \times$ $1.956 \mathrm{~mm}^{2}$. The interscans time interval was $15 \mathrm{~min}$. In addition to the PET data, a series of axial and sagittal 3-mm-thick T1-weighted highresolution MRIs covering the whole brain were acquired for each subject on a $0.5 \mathrm{~T}$ GE-MRMAX imager.

\section{Data analysis}

The data were analyzed for the group of five subjects through intersubject averaging and also for each individual subject separately. The group 
analysis provided information about averaged regional changes in the distribution of relative blood flow. The individual analysis provided information relevant to the investigation of structure-function relationships and their individual variability. As a preprocessing step, the Automated Image Registration package was used to perform individual PETPET (Woods et al., 1992) and PET-MRI registrations (Woods et al., 1993).

SPMs. SPMs of the $t$ statistics corresponding to comparison of SEQ, SAC, and REST tasks were tested with the three-dimensional (3-D) version of SPM (Friston, 1995). The original brain images were transformed into the standard stereotactic Talairach space (Talairach and Tournoux, 1988). Global differences in the CBF within and between subjects were covaried out, and comparisons across conditions were made by way of $t$ statistics (Friston et al., 1991, 1994). The Z volume is projected in three orthogonal directions, sagittal, coronal, and transverse, and the threshold was set at $\mathrm{Z}=3.1(p<0.001$, not corrected for multiple comparisons). The experimental protocol was designed to use successively each one of the REST and SAC tasks as a reference condition. Thus, significant increases, as compared with the resting control condition (SAC vs REST, SEQ vs REST), uncovered the activation attributable to either common oculomotor processing shared by both tasks or to operations specific to the exceution of self-paced or prelearned saccades sequences. Significant differences between saccadic tasks (SEQ vs SAC) then indicated the areas that were specifically involved in the execution of prelearned sequences of saccades. The coordinates and the spatial extent in the stereotactic spacc of activated areas are given in Tables 1-3.

Single-case analysis (HMSD analysis). The data were also processed using a software capable of detecting activation, location, and extension in single subjects. This method, HMSD, has been detailed extensively in a previous publication (Poline and Mazoyer, 1994). Briefly, it is based on a hicrarchical description of the PET difference image into connected objects. This description is performed for different image resolutions, with a multiscale filtering strategy. At each resolution, the probabilities of occurrence of connected objects are assessed by testing their size and amplitude simultancously with respect to a Monte Carlo-derived bidimensional frequency distribution established under the null hypothesis, an iterative procedure used to control the overall type I error. Once an object is labeled as significant, it is removed from the currently processed image by setting every one of its voxels to the smallest value. This procedure avoids having an object that is detected at a high-resolution scale also detected at a lower one and thus leads to a better object spatial delimitation. The HMSD detection algorithm was applied to the individual NrCBF difference images averaged across the two replicates. The significance level was set at 0.2 per plane after a Bonferroni correction. This somewhat permissive threshold was chosen because the HMSD approach was used in the present study only to obtain additional information on the exact locations of the activated foci detected by the SPM software rather than as a detection software per se. The statistical threshold applied to each cluster defined by the hierarchical description was assessed by estimating first the number of voxels composing the gray matter in each plane of the brain and then the number of independent comparisons made in the Bonferroni correction.

An accurate localization of the objects detected with the HMSD method was made by a detailed anatomical analysis of the brain anatomy of each subject. With use of a dedicated software (Voxtool, General Electric, Buc, France), MRI axial slices were used to reconstruct a 3-D brain volume that was segmented further and thus allowed the display of the surfaces of both hemispheres together with sections in three orthogonal directions (Mazoyer et al., 1993). The principal sulci were identified in the MRI of each subject (see Results). In particular, we localized the intraparietal sulcus using the following description: this sulcus originates in the postcentral sulcus and ends on the convexity delineating the lateral and medial part of the superior parietal gyrus (Eidelberg and Galaburda, 1984).

\section{RESULTS}

We will first describe the EOG recordings used to check on the correct execution of the requested tasks and will then present the different areas activated in each task with both SPM and HMSD analyses.

\section{EOG analysis}

In four of the five subjects, EOG recordings were usable for processing. During the SAC condition, the subjects, in total dark- ness, executed maximum large-amplitude, voluntary, self-paced horizontal saccades that were symmetric with respect to the primary eye position. The mean frequency of these saccadic eye movements was $3.0 \mathrm{~Hz}$ (range, $2.3-4.5 \mathrm{~Hz}$ ). The mean amplitude of saccades was $36^{\circ}$ (range, $31-41^{\circ}$ ), with respect to the primary central eye position.

The execution of the SEQ condition has been analyzed extensively in a previous study with other human subjects (Israël et al., 1993). In the present work, the detailed study of the EOG recordings shows that all of the subjects executed one type of sequence, always the same during one condition, even when at times it was not exactly the sequence they had been asked to memorize. Figure 2 presents both the saccades sequences that the subjects had to memorize and the averaged sequences they executed during the PET data acquisition period. All exccuted sequences were hypermetrical. For three of the four analyzed subjects, the averaged number of executed sequences of saccades was 13.5 per rCBF data acquisition (range, 9-16), with an averaged duration ranging from 5.8 to $8.6 \mathrm{sec}$. In addition, as illustrated in Figure 2, subject $\mathrm{S} 4$ executed a sequence with only four memorized saccades, which led him to execute a greater number of sequences ( 48 for sequence 1, 31 for sequence 2 ) with a shorter averaged duration (1.8 sec and $3.4 \mathrm{sec}$, respectively). Therefore, all of the four subjects executed horizontal saccades at an averaged frequency of $0.9 \mathrm{~Hz}$ (range, $0.5-1.8 \mathrm{~Hz}$ ).

To summarize, once in total darkness, each subject repeated a sequence of large saccades, always the same, during the 2 min of the PET data acquisition.

\section{SPM analysis}

Results obtained with the SPM analysis are illustrated in Figure 3, and Tables 1-3 show the characteristics of the regions activated with their spatial extent and peak value. The data set for the five subjects extended from $20 \mathrm{~mm}$ below the anterior commissureposterior commissure (AC-PC) line to $52 \mathrm{~mm}$ above it. The foci of activation are detailed below for the following comparisons: SEQ versus REST, SAC versus REST, SEQ versus SAC.

\section{SEQ versus REST (Table I)}

When the repetition of prelearned saccades sequences was compared directly with the REST condition, we noticed a significant increase of the $\mathrm{NrCBF}$ in the medial part of the superior frontal gyrus, at the level of the supplementary motor area (SMA), corresponding to the SEF activation (6.6\%). In addition, a strong activation was observed in the median cingulate gyrus (7.6\%). A significant bilateral activation was also noticed in the precentral gyrus, which corresponds to the frontal eye ficld (FEF) activation (left, $5.5 \%$; right, $4.2 \%$ ). The latter was symmetrical, with a maximum positioned at $40 \mathrm{~mm}$ above the AC-PC line on both the right and left hemispheres. The strongest significant activation was located at the depth of the right superior frontal sulcus $(9.0 \%)$, close to the precentral sulcus, with a maximum voxel clearly distinct from those observed in the precentral gyrus. At the parietal level, bilateral significant activation was detected in the superior parietal gyrus, close to the intraparietal sulcus (left, $6.9 \%$; right, $5.0 \%$ ) and the precuneus $(8.4 \%)$. A consistent activation was also observed in the left insula (5.0\%). At the subcortical level, one could notice a significant and bilateral increase of the lenticular nucleus, centered on the putamen (left, $4.3 \%$; right, $5.4 \%$ ). Finally, a significant activation of the cerebellar vermis $(6.7 \%)$ extending over the adjacent right cerebellar cortex $(4.3 \%)$ was also observed. 


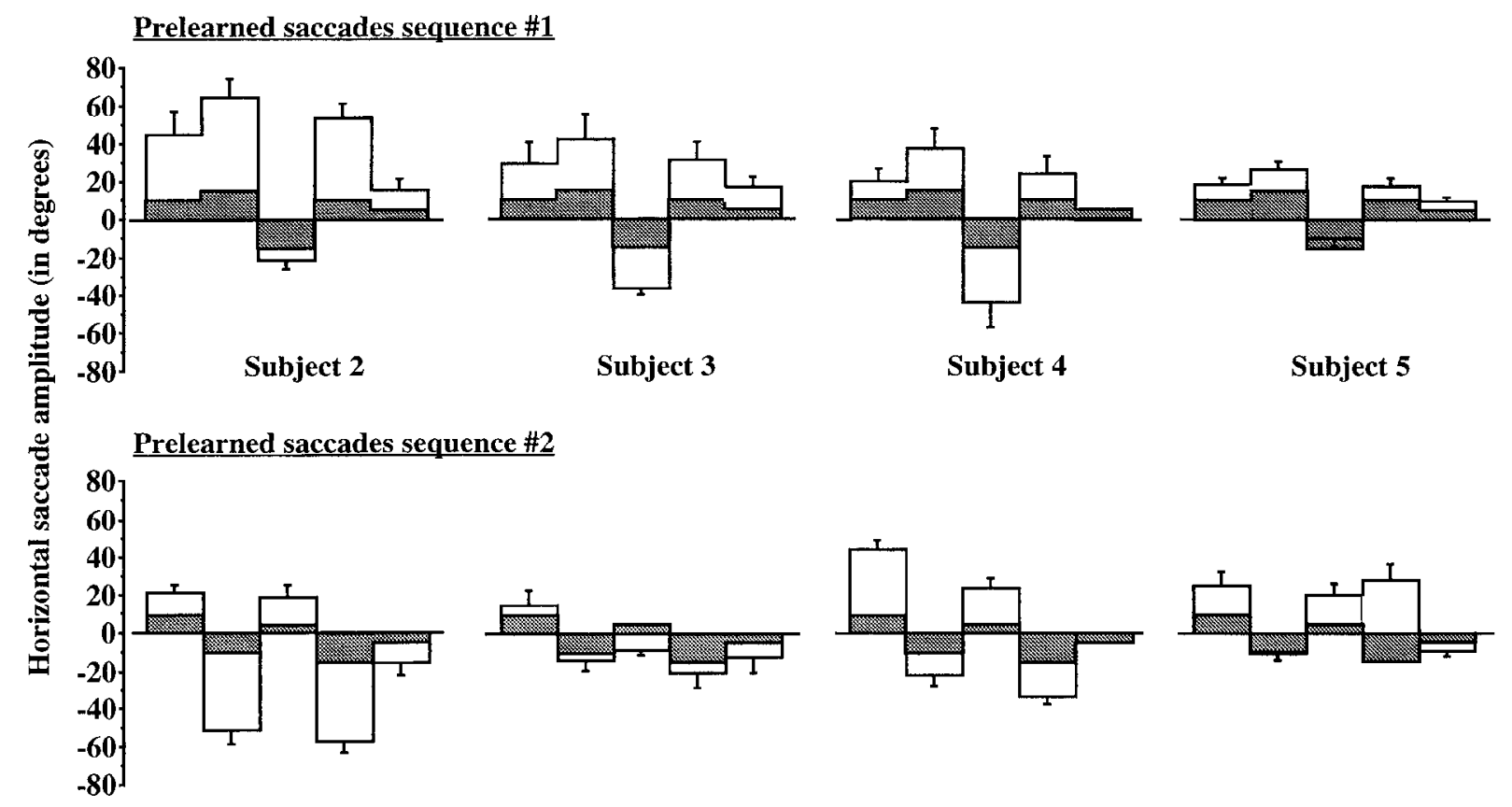

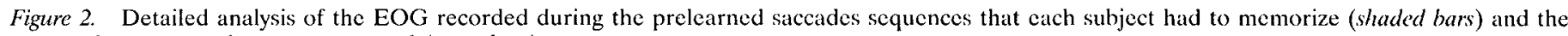
averaged sequences that were executed (open bars).

\begin{tabular}{|c|c|c|c|c|c|}
\hline Activated areas & & $\begin{array}{l}\% \text { change } \\
\text { in } \mathrm{NrCBF}\end{array}$ & Z score & $\begin{array}{l}\text { Talairach } \\
\text { coordinates of } \\
\text { local maxima }\end{array}$ & $\begin{array}{l}\text { Extent of area activated } \\
\text { (relative to AC-PC line) }\end{array}$ \\
\hline Supplementary motor area & & 6.6 & 5.4 & $+8,+8,+52$ & +52 to $+40 \mathrm{~mm}$ \\
\hline Median cingulum & & 7.6 & 5.4 & $-6,+4,+44$ & +44 to $+28 \mathrm{~mm}$ \\
\hline \multirow[t]{2}{*}{ Precentral gyrus } & $\mathrm{L}$ & 5.5 & 3.9 & $-44,-6,+40$ & +48 to $+36 \mathrm{~mm}$ \\
\hline & $\mathbf{R}$ & 4.2 & 3.5 & $+40,-6,+40$ & +48 to $+36 \mathrm{~mm}$ \\
\hline Superior frontal sulcus & $\mathbf{R}$ & 9.0 & 4.4 & $+20,-10,+48$ & +52 to $+44 \mathrm{~mm}$ \\
\hline \multicolumn{6}{|l|}{ Superior parietal gyrus/ } \\
\hline \multirow[t]{2}{*}{ intraparictal sulcus } & $\mathrm{L}$ & 6.9 & 5.1 & $-16,-72,+44$ & +48 to $+32 \mathrm{~mm}$ \\
\hline & $\mathbf{R}$ & 5.0 & 3.4 & $+34,-44,+40$ & +48 to $+36 \mathrm{~mm}$ \\
\hline Precuneus & & 8.4 & 5.7 & $+4,-76,+40$ & +48 to $+32 \mathrm{~mm}$ \\
\hline Insula & $\mathrm{L}$ & 5.0 & 3.8 & $-34,+8,+8$ & +12 to $0 \mathrm{~mm}$ \\
\hline \multirow[t]{2}{*}{ Putamen } & $\mathbf{L}$ & 4.3 & 3.5 & $-24,-12,+8$ & +12 to $+4 \mathrm{~mm}$ \\
\hline & $\mathbf{R}$ & 5.4 & 4.4 & $+26,+6,+12$ & +12 to $+8 \mathrm{~mm}$ \\
\hline Cerebellar vermis & & 6.7 & 4.5 & $-10,-74,-20$ & -8 to $-20 \mathrm{~mm}$ \\
\hline Cerebellar cortex & $\mathbf{R}$ & 4.3 & 3.2 & $+50,-58,-20$ & $-16 \mathrm{to}-20 \mathrm{~mm}$ \\
\hline
\end{tabular}

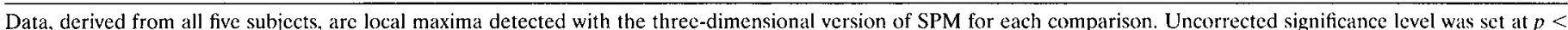

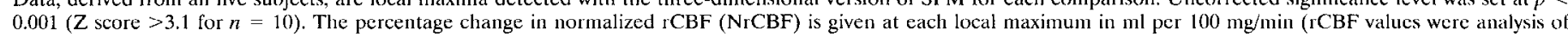
covariance-adjusted to grand global mean flow and then ratio-adjusted to global mean flow of 50 ).

\section{SAC versus REST (Table 2)}

Part of the areas activated by the repetition of prelearned saccades sequences was also activated during the execution of selfpaced horizontal saccades, as conpared with the REST condition. There was a significant $\mathrm{NrCBF}$ increase in the SEF (6.6\%), as well as in the median cingulate gyrus $(6.1 \%)$. An extensive and significant activation of the FEF (left, $7.9 \%$; right, $4.8 \%$ ) was also observed at the level of the precentral gyrus. Such a precentral activation was quite asymmetrical, with a maximum positioned at $40 \mathrm{~mm}$ to the right and $44 \mathrm{~mm}$ to the left, above the AC-PC line. A weaker activation was also observed in the right insula (3.2\%). At subcortical level, a significant and bilateral increase was noted at the level of the lenticular nucleus centered on the putamen (left, $4.1 \%$; right, $3.8 \%$ ), as well as an activation of the right thalamus (3.7\%). Finally, a significant activation of the cerebellar vermis $(6.1 \%)$ was also observed. These results, observed previously in similar comparisons (Petit et al., 1993; Lang et al., 1994), allowed us to consider the SAC condition as a reference task in a third comparison designed to specify activated areas related to the performance of prelearned saccades sequences.

\section{SEQ versus $S A C$ (Table 3 )}

When the repetition of prelearned saccades sequences was compared with the execution of self-paced saccades, there was a 


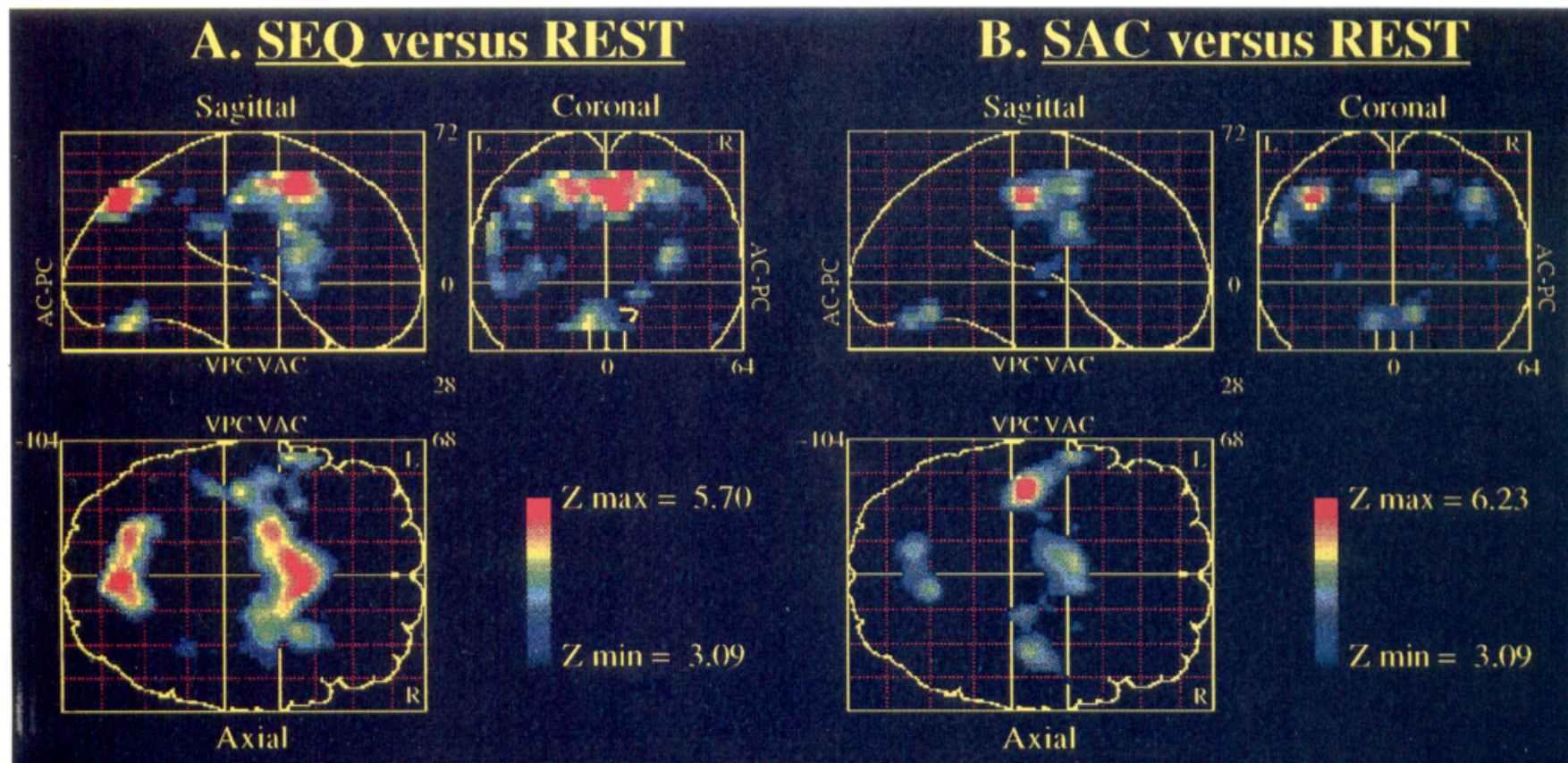

\section{SEO versus SAC}
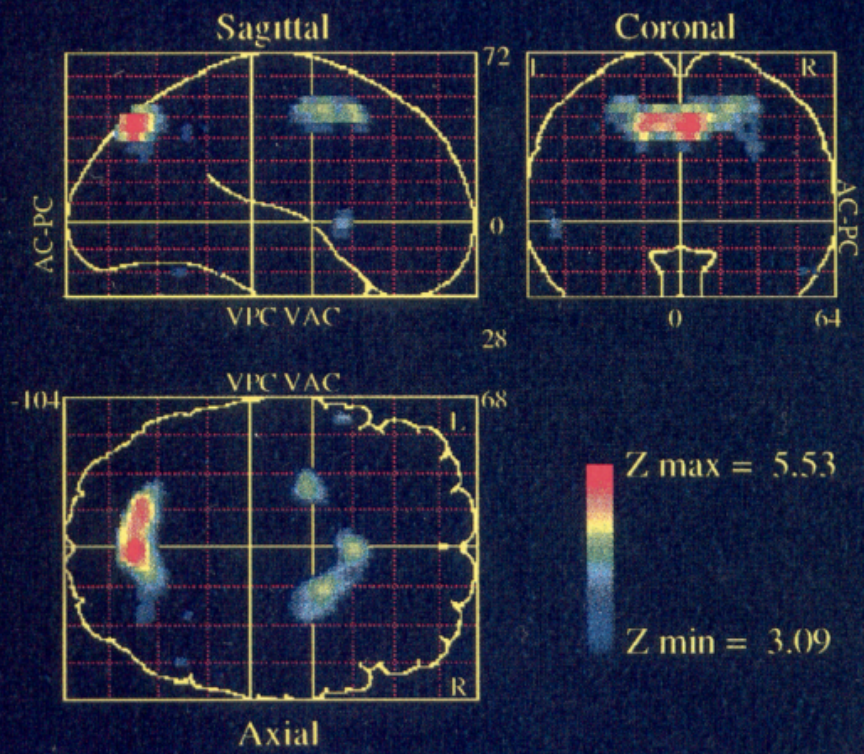

Figure 3. SPMs for three comparisons. A, SEQ versus REST; B, SAC versus REST; C, SEQ versus SAC. Significant pixels at the given threshold of $p<$ 0.001 uncorrected for multiple comparisons are displayed on single sagittal, coronal, and axial projections of the brain. The spatial location of each activated area can be established by comparing its position in the three views: $A C-P C$, anterior commissure-posterior commissure plane; $V A C$, $V P C$, vertical plane passing through the anterior and posterior commissure, respectively.

significant $\mathrm{NrCBF}$ increase at the level of the SMA $(4.2 \%)$, with a maximum peak value clearly rostral to that observed in the above-mentioned comparisons. At the frontal level, there was also a bilateral, significant $\mathrm{NrCBF}$ increase in the depth of the superior frontal sulcus (left, $7.2 \%$; right, $6.0 \%$ ) close to the precentral sulcus. At the parietal level, bilateral significant activations were found in the superior parietal gyrus close to the intraparietal sulcus (left, $6.6 \%$; right, $5.2 \%$ ). The precuneus was also strongly activated $(7.7 \%)$.
No significant difference between the two saccade tasks was observed at the level of the basal ganglia or the cerebellum.

To summarize, the SPM data analysis permitted distinction of a set of cortical and subcortical activations during both the repetition of prelearned saccades sequences and the execution of self-paced saccades. At the cortical level, this network was composed of the SEF, the median part of the cingulate gyrus, the FEF, and the insula. At the subcortical level, the lenticular nucleus (putamen and globus pallidus) and the thalamus were 


\begin{tabular}{|c|c|c|c|c|c|}
\hline Activated areas & & $\begin{array}{l}\text { \% change } \\
\text { in } \mathrm{NrCBF}\end{array}$ & $Z$ score & $\begin{array}{l}\text { Talairach } \\
\text { coordinates of } \\
\text { local maxima }\end{array}$ & $\begin{array}{l}\text { Extent of area activated } \\
\text { (relative to AC-PC line) }\end{array}$ \\
\hline Supplcmentary motor arca & & 5.8 & 4.2 & $+8,+4,+52$ & +52 to $+40 \mathrm{~mm}$ \\
\hline Median cingulum & & 6.1 & 4.8 & $-4,+2,+44$ & +44 to $+40 \mathrm{~mm}$ \\
\hline \multirow[t]{2}{*}{ Precentral gyrus } & $\mathrm{L}$ & 7.9 & 6.2 & $-40,-22,+40$ & +48 to $+32 \mathrm{~mm}$ \\
\hline & $\mathrm{R}$ & 4.8 & 4.7 & $+38,-20,+44$ & +48 to $+32 \mathrm{~mm}$ \\
\hline Insula & $\mathrm{R}$ & 3.2 & 3.4 & $+44,-6,+8$ & +20 to $+8 \mathrm{~mm}$ \\
\hline \multirow[t]{2}{*}{ Putamen } & $\mathrm{L}$ & 4.1 & 3.6 & $-28,-14,+4$ & +8 to $+4 \mathrm{~mm}$ \\
\hline & $\mathrm{R}$ & 3.8 & 3.3 & $+26,+2,+8$ & +12 to $+4 \mathrm{~mm}$ \\
\hline Thalamus & $\mathbf{R}$ & 3.7 & 3.4 & $+18,-10,+8$ & $+8 \mathrm{~mm}$ \\
\hline Cerebellar vermis & & 6.1 & 4.6 & $+8,-64,-12$ & -8 to $-20 \mathrm{~mm}$ \\
\hline
\end{tabular}

See legend to Table 1 for details.

\begin{tabular}{|c|c|c|c|c|c|}
\hline Activated areas & & $\begin{array}{l}\% \text { change } \\
\text { in } \mathrm{NrCBF}\end{array}$ & Z score & $\begin{array}{l}\text { Talairach } \\
\text { coordinates of } \\
\text { local maxima }\end{array}$ & $\begin{array}{l}\text { Extent of area activated } \\
\text { (relative to AC-PC line) }\end{array}$ \\
\hline Supplementary motor arca & & 4.2 & 4.3 & $+2,+14,+48$ & +52 to +40 \\
\hline \multirow[t]{2}{*}{ Superior frontal sulcus } & $\mathrm{L}$ & 7.2 & 4.1 & $-24,-4,+48$ & +52 to +44 \\
\hline & $\mathrm{R}$ & 6.0 & 4.3 & $+18,+4,+48$ & +52 to +44 \\
\hline \multicolumn{6}{|l|}{ Superior parietal gyrus/ } \\
\hline \multirow[t]{2}{*}{ intraparietal sulcus } & $\mathbf{L}$ & 6.6 & 5.0 & $-14,-72,+44$ & +48 to +32 \\
\hline & $\mathrm{R}$ & 5.2 & 3.4 & $+30,-72,+32$ & +48 to +32 \\
\hline Precuneus & & 7.7 & 5.5 & $+2,-76,+40$ & +48 to +32 \\
\hline
\end{tabular}

See legend to Table 1 for details.

consistently activated, as was the cerebellar vermis. In addition, the execution of prelearned saccades sequences led to specific $\mathrm{NrCBF}$ increases in the depth of the superior frontal sulcus as well as in the rostral part of the SMA, whereas at the parietal level, an important activation was observed in the intraparietal sulcus extending to the precuneus.

\section{HMSD analysis}

An analysis of the data obtained with each subject by the HMSD method allowed us to define in more detail the anatomy of activated areas. Figures 4 and 5 show the detailed anatomical analysis for four subjects where the activated sulcal areas are clearly visible when the repetition of prelearned saccades sequences was compared directly with the resting control condition. The detected activations were superimposed on the corresponding axial MRI slice after sulcal identification.

\section{SEQ versus REST (Table 4)}

Activations detected in the parietal cortex were centered mainly in the posterior part of the intraparietal sulcus, in the area located between the medial and the lateral part of the superior parietal gyrus. Subjects S2 and S3 showed an extensive bilateral activation along the whole of the intraparietal sulcus and up to the supramarginal gyrus.

Considering the averaged results, no significant activation could be detected in the left precuneus during the performance of a prelearned saccades sequence when compared with REST. The individual analysis, however, showed that four of the subjects presented a left precuneus activation (Table 4). Regarding their distribution, these detected activations of the precuneus appeared as an extension of the detected activation centered at the depth of the intraparietal sulcus (Figs. 4, 5).

In the case of three subjects, significant activations were detected in the depth of the superior frontal sulcus. In subjects S1, $\mathrm{S} 2$, and S5, the superior frontal activations were close to the anastomosis between the superior frontal sulcus and the precentral sulcus, whereas subject S3 showed a more anterior and superior frontal sulcus activation. Nevertheless, the supcrior frontal activation is different from the more caudal precentral gyrus activation. As illustrated in Figure 4, subjects S1 and S2 clearly showed a distinct precentral and superior frontal activation during SEQ versus REST comparison.

With all subjects, we detected significant activations in the medial wall of the superior frontal gyrus corresponding to the SEF activation. Similarly, a median cingulate activation was observed in the case of all subjects (Table 4). All of these median activations were symmetrical, and each median cingulate activation was underlying that observed at the SEF level. In three of the five subjects, the significant activations detected bilaterally in the precentral gyrus corresponded to the FEF activation; they overlapped the precentral gyrus $42 \mathrm{~mm}$ above the bicommissural plane.

Additional cortical activations were detected in the left insular cortex with four subjects (S1, S3, S4, S5) in the SEQ versus REST comparison, whereas right insular activated areas were observed with subjects S1 and S5. All of these insular activations were 


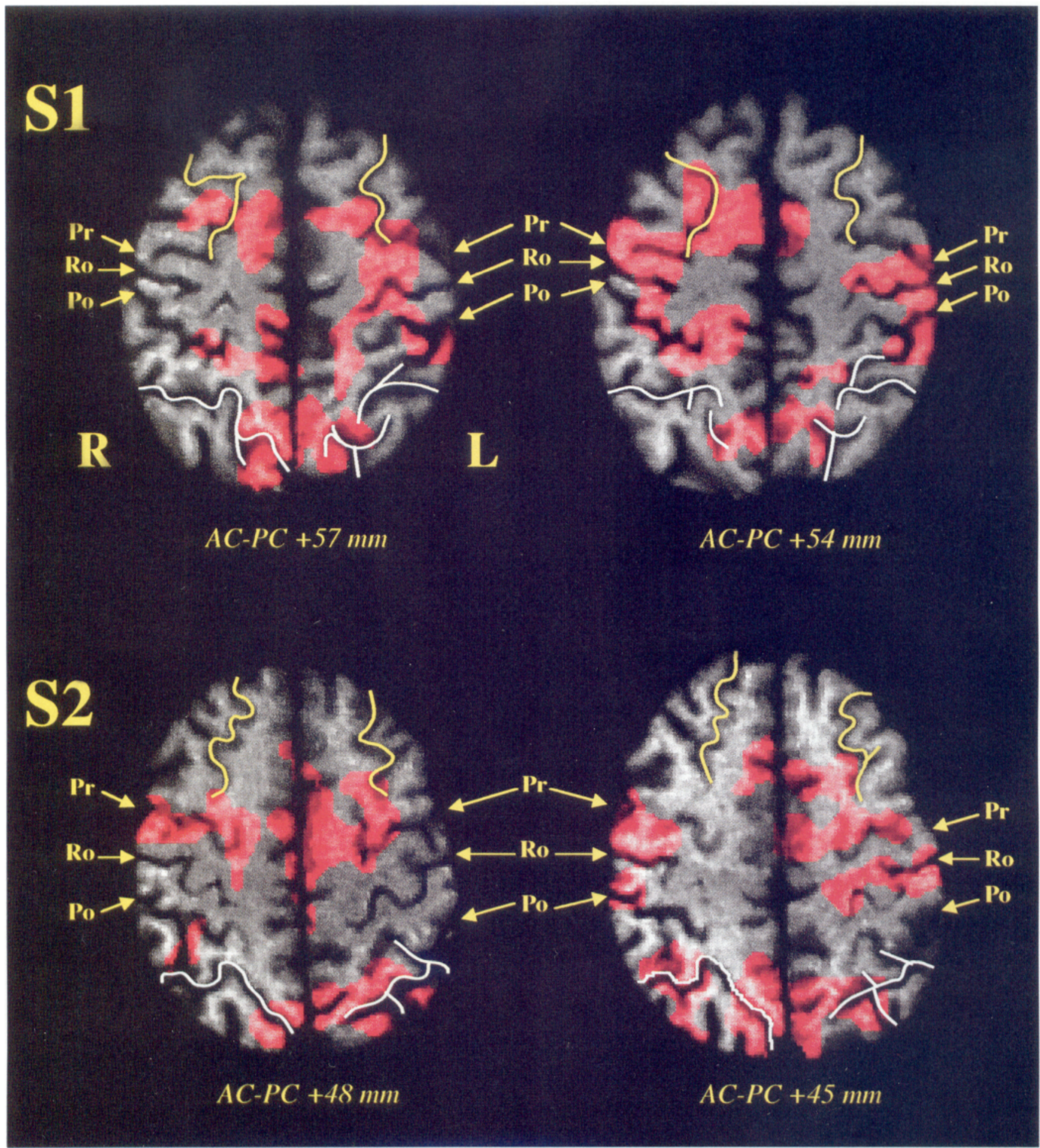

Figure 4. HMSD results for subjects S1 and S2 when the repetition of prelearned saccades sequences was compared directly with the resting control condition. After alignment of the MRI and PET volumes in the same coordinates space, the different detected objects are superimposed on their corresponding axial MRI slice for each subject. A detailed anatomical analysis after sulcal identification allows accurate localization of these activations. Superior frontal sulcus (yellow); intraparietal sulcus (white); Ro, Rolandic sulcus; $P r$, precentral sulcus; $P o$, postcentral sulcus; $R$, right; $L$, left; $A C-P C+x$ $\mathrm{mm}$, axial plane $\mathrm{x} \mathrm{mm}$ above the bicommissural plane. Details of the detected objects are given in Results.

located in the anterior part of the insula at the level of the vertical AC line.

At the subcortical level, significant activations were detected in the lenticular nucleus as well as in the thalamus (Table 4). Acti- vations overlapping both the putamen and the globus pallidus were observed in the SEQ versus REST difference in the right (S1 and S2) and the left (S1 and S5) hemisphere. Thalamic activations were also detected bilaterally with subject S1. 


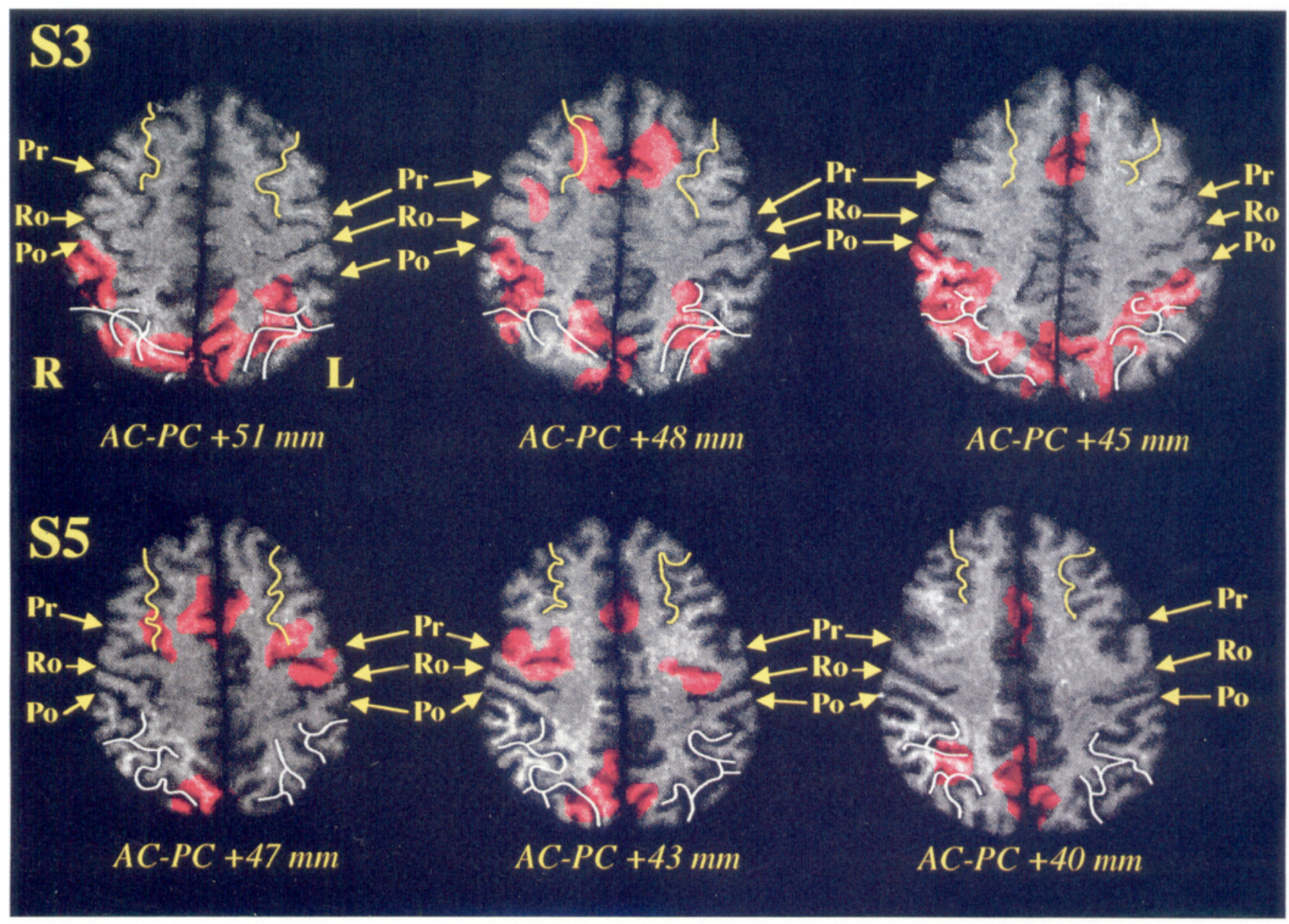

Figure 5. HMSD results for subjects S3 and S5 when the repetition of prelearned saccades sequences was compared directly with the resting control condition. See Figure 4 legend for details.

Finally, large detected activations centered on the cerebellar vermis were also observed in three of the subjects (S1, S2, S5) in the SEQ versus REST comparison.

\section{SAC versus REST (Table 4)}

A part of the detected activation related to the repetition of prelearned saccades sequences was also detected during the exe-

\section{Table 4. Number of subjects (5) in whom significant activations were detected by HMSD and their anatomical localization in the three} comparisons

\begin{tabular}{|c|c|c|c|c|c|c|}
\hline \multirow[b]{2}{*}{ Activated areas } & \multicolumn{2}{|c|}{$\begin{array}{l}\text { SEQ vs } \\
\text { REST }\end{array}$} & \multicolumn{2}{|c|}{$\begin{array}{l}\text { SAC vs } \\
\text { REST }\end{array}$} & \multicolumn{2}{|c|}{$\begin{array}{l}\text { SEQ vs } \\
\text { SAC }\end{array}$} \\
\hline & $\mathrm{L}$ & $\mathrm{R}$ & $\mathrm{L}$ & $\mathrm{R}$ & $\mathrm{L}$ & $\mathrm{R}$ \\
\hline Supplementary motor area & \multicolumn{2}{|c|}{5} & \multicolumn{2}{|c|}{5} & \multicolumn{2}{|c|}{2} \\
\hline Median cingulum & \multicolumn{2}{|c|}{5} & \multicolumn{2}{|c|}{4} & \multicolumn{2}{|c|}{1} \\
\hline Precentral gyrus & 4 & 3 & 5 & 4 & 0 & 0 \\
\hline Superior frontal sulcus & 3 & 4 & 0 & 1 & 3 & 2 \\
\hline Intraparietal sulcus & 3 & 4 & 1 & 1 & 4 & 5 \\
\hline Precuneus & 4 & 4 & 1 & 2 & 4 & 4 \\
\hline Insula & 4 & 2 & 3 & 1 & 3 & 1 \\
\hline Lenticular nucleus & 3 & 1 & 2 & 3 & 1 & 0 \\
\hline Thalamus & 2 & 2 & 1 & 2 & 1 & 1 \\
\hline Cerebellar vermis & \multicolumn{2}{|c|}{3} & \multicolumn{2}{|c|}{3} & \multicolumn{2}{|c|}{0} \\
\hline
\end{tabular}

Detected objects at $p<0.2$ per plane. cution of self-paced horizontal saccades as compared with the REST condition.

In all subjects, significant symmetrical activations were detected in the medial wall of the superior frontal gyrus corresponding to the SEF activation. A median cingulate activation underlying that observed at the SEF level was also observed, except for subject S1 (Table 4). In four of the five subjects, significant activations were detected bilaterally in the precentral gyrus $42 \mathrm{~mm}$ above the bicommissural plane, and they corresponded to the FEF activation.

In the SAC versus REST comparison, insular activations, located in the anterior part of the insula, were also detected in the left (S1, S3, S5) and right (S2) hemispheres.

At the subcortical level, of the five subjects, S2, S3, and S4 showed a right lenticular activation, and S3 and S5 showed a left one. All of these activations overlapped both the putamen and the globus pallidus. In addition, a bilateral thalamic activation was observed with subject S5.

Finally, subjects S2, S3, and S5 showed a symmetrical cerebellar vermis activation in the SAC versus REST comparison.

\section{SEQ versus $S A C$ (Table 4)}

When the repetition of prelearned saccades sequences was compared with the execution of self-paced saccades, subjects S1 and S2 showed a medial wall activation located more rostrally than the activations observed in the above-mentioned comparisons. 
Significant activations were also detected in the depth of the superior frontal sulcus, bilaterally with subjects S1 and S5. These superior frontal activations were close to the anastomosis between the superior frontal sulcus and the precentral sulcus. As indicated in Table 4, no precentral activation was detected when the performance of prelearned saccades sequence was compared with the self-paced saccades execution, whereas the superior frontal sulcus activation was still present. Thus, the superior frontal activation is different from the more caudal precentral gyrus activation.

At the parietal level, bilateral activations centered in the posterior part of the intraparietal sulcus were detected in at least four of the five subjects in the SEQ versus SAC comparison. As mentioned above, the significant activations detected bilaterally in the precuneus in four of the five subjects (Table 4) corresponded to the extension of the detected activation centered at the depth of the intraparietal sulcus.

Additional left (S1, S2, S5) and right (S3) insular activation were also detected. At the subcortical level, subject S1 showed a left lenticular and a bilateral thalamic activation when the prelearned saccades sequences was compared with the execution of self-paced saccades.

To summarize, present individual results support the averaged results of a common set of cortical and subcortical areas activated during both the repetition of prelearned saccades sequences and the execution of self-paced saccades as compared with the resting control condition (SEQ vs REST, SAC vs REST; Table 4). In addition, individual results were of special interest with regard to the activations of specific prelearned saccades sequences within both the superior frontal and the intraparietal sulci.

\section{DISCUSSION}

\section{Task execution}

Both the mean amplitude and the frequency of the execution of self-paced horizontal saccades were similar to those described previously (Petit et al., 1993; Lang et al., 1994).

Regarding the repetition of prelearned saccades sequences, the analysis of EOG recordings showed that all subjects executed one sequence only, and always the same one, during all of the $\mathrm{NrCBF}$ measures. In most cases, this sequence was similar to the requested one with regard to both timing and direction of saccades; however, saccades were generally hypermetrical and the mean duration of the sequence was shorter than requested. Hypermetry of memorized saccades executed in total darkness was noted previously in humans (Becker and Fuchs, 1969; Körner, 1975; Zingale and Kowler, 1987; Israël, 1992) but remains unexplained. Becker and Klein (1973) have offered two suggestions to account for this hypermetry: (1) the larger the saccades, the better the subject's ability to perceive the change of the eye position in darkness, and (2) in natural circumstances, the only nonvisually guided saccades are those directed toward nonidentified peripheral stimuli outside the visual field, resulting in very large saccades.

In any case, EOG recordings during the repetition of prelearned saccades sequences seem to indicate that the memorization action concerned the saccadic and sequential movements rather than the exact end-position of the targets.

\section{A parietofrontal spatial vision system}

The main result of the present study is that the repetition of a prelearned sequence of saccades in total darkness leads specifically to a bilateral activation at the depth of both intraparietal and superior frontal sulci as well as at the rostral part of the SEF, added to the set of cortical and subcortical activations described previously during the execution of horizontal saccades (Paus et al., 1993; Petit et al., 1993; Lang et al., 1994; Anderson et al., 1994; O'Sullivan et al., 1995; Sweeney et al., 1996).

\section{Intraparietal sulcus}

The repetition in total darkness of a prelearned sequence of horizontal saccades leads to a bilateral increase at the depth of the intraparietal sulcus extending toward both the lateral and the medial superior parietal cortex, i.e., the superior parietal gyrus and the precuneus, respectively. It has long been proposed that the superior parietal cortex comprising the intraparietal sulcus plays an important part in the treatment of saccades oriented toward a visual target. The ncurologist Rudolf Balint was the first to describe a patient suffering from a bilateral posterior parietal lesion underlying deficiencies in the eye movements (Balint, 1909). This patient showed an inability to execute voluntary saccades, whereas the execution of spontaneous saccades was not affected in any way. Since this pioneering study, numerous examples of deficiencies in voluntary saccades aimed at visual targets after biparietal lesions have been reported in clinical literature. Unilateral lesions often result in attention and spatial deficiencies limited to the contralateral space and sometimes can also lead to a deficit in eye movements. Numerous works have confirmed the importance of the integrity of the superior parictal cortex in the execution of visually guided voluntary saccades and the orientation of attention (Holmes, 1938; Hecaen and De Ajuriaguerra, 1954; Luria et al., 1963; Rondot and De Recondo, 1974). Particular notice has been taken of an increase of latency and a loss of accuracy in visually guided (Pierrot-Deseilligny et al., 1987, 1988, 1991a) or memorized (Pierrot-Deseilligny et al., 1991b) saccades in patients suffering from lesions of the superior parietal cortex.

Single-cell recording experiments in the monkey led to a better understanding of the exact role played by the superior parietal cortex in the production of saccades. The results of these studies have suggested that the functional role of the superior parietal cortex involves the programming of saccades based on sensory information (for review, see Andersen and Gnadt, 1989). Another important finding was the discovery of an area located at the depth of the intraparietal sulcus, the lateral intraparietal region (LIP), which seems to be connected more particularly with saccadic movements (Shibutani et al., 1984; Gnadt and Andersen, 1988). In particular, LIP neurons have shown a strong tonic activity representing the signal coding for the planning of a memorized saccade (Gnadt and Andersen, 1988). The temporal relationship of the activity of these neurons to animal behavior has suggested that the activity of these neurons represents the intention of making a saccade within a given direction and at a given amplitude (Duhamel et al., 1992).

In the present study, the HMSD analysis supplied the first evidence of an accurate localization of activations at the depth of the intraparietal sulcus (Figs. 4, 5), although the present limited spatial resolution of our PET tomograph did not permit the observation of an intraparietal activation more specifically localized on the lateral bank of this sulcus. Anderson et al. (1994) recently described a bilateral activation of the superior parietal cortex, medial to the intraparietal sulcus, resulting from the execution of both visually and memory-guided saccades. On the 
contrary, previous PET studies on eye movements have not shown any parietal activation during the execution of self-paced voluntary saccades (Petit et al., 1993; Lang et al., 1994) or during the motor imagery of saccades (Lang et al., 1994), i.e., when the saccadic eye movements were not sensory-guided.

In sumnary, the fact that the intraparietal activation was observed only during the execution of saccades set on the basis of either internally or externally cued visual targets confirms the crucial role of this structure in the coding of this type of movement. More specifically, as shown previously with the monkey (Barash et al., 1991), these findings may suggest that the intraparietal sulcus in human subjects plays a role in higher level processes related to planning of saccades rather than to the control of the execution of such movements.

\section{Superior frontal sulcus}

A bilateral activation at the depth of the superior frontal sulcus was noticed during the execution of prelearned saccades sequences. The location of such an activation, anatomically identified in each subject in front of the precentral gyrus, overlaps Brodmann's areas 6 and 8 , which makes a designation of prefrontal or premolor cortex difficult. With regard to the localization of the NrCBF maximum increases, the activation of the superior frontal sulcus differs from that of the precentral gyrus and therefore cannot be attributed to an extension of the activity of the FEF (see below). In addition, a similar superior frontal activation was not detected during the execution of other types of saccades (Fox et al., 1985a; Petit et al., 1993; Anderson et al., 1994; Lang et al., 1994; O'Sullivan et al., 1995; Sweeney et al., 1996).

Other PET studies, however, described superior frontal arcas close to the superior frontal sulcus activations observed in the present study. According to Passingham (1988), such a cortical region acts after the current situation determined by both the sensory information still available and the information still present in the task memory. A recent PET study demonstrated that working memory in the frontal lobe of humans, like that of the monkey, is functionally segregated, with a dorsal region for spatial location and more ventral regions for object identity (Courtney et al., in press). Interestingly, the dorsal frontal area activated by spatial working memory was in the superior frontal sulcus. The same superior frontal activation has been seen in several different studies of spatial working memory (Jonides et al., 1993; Haxby et al., 1994). Moreover, Mellet et al. (1995) recently described a bilateral superior frontal sulcus activation when subjects had to construct mental images of 3-D cube assemblies on the basis of auditorily presented directional words. In our protocol, the prelearned task undoubtedly has a mnemonic component similar to spatial working memory. Consequently, the superior frontal activation in the current study clearly can be attributed to the need for maintaining an internal representation of spatial information, i.e., an activation of motor memory as defined by Fuster (1995). Although the designation of prefrontal or premotor cortex remains ambiguous, what is clear is that such a region at the depth of the superior frontal sulcus can be defined functionally as spatial working-memory area.

\section{The dorsal spatial vision pathway}

Several PET studies examining other spatial vision tasks identified superior parietal and frontal activations associated with spatial shift of attention (Corbetta et al., 1993, 1995), working memory for visuospatial location (Jonides et al., 1993; Haxby et al., 1994; Courtney et al., in press), and object location matching (Haxby et al., 1991, 1994). Other recent PET studies have described both superior parietal and frontal activations either during a complex visuospatial cognitive task, i.e., a perceptual maze test (Ghatan et al., 1995), or during a verbally guided construction of 3-D mental objects (Mellet et al., 1995). These other superior parietal and frontal activations are in close proximity to the areas activated in the present study by prelearned saccades sequence execution.

Initially described in the monkey (Mishkin et al., 1983), and later with PET in humans (Haxby et al., 1991), the dorsal vision pathway is constituted by functional areas involved in the spatial processing of visual information linking the extrastriate visual areas to the superior parietal cortex. The PET studies mentioned above have accumulated evidence demonstrating that the intraparietal sulcus represents the superior parietal component of such a dorsal stream, whereas the superior frontal sulcus represents the frontal part. This is consistent with the early proposal that perceptual and intentional components of spatial information are mediated through superior parietal and frontal areas, respectively (Mesulam, 1981, 1990).

\section{SEFS}

An NrCBF increase related to the SEF activation was noticed at the level of the supplementary motor area during the repetition of prelearned saccades sequences as well as during the execution of self-paced saccades. These findings confirmed the data obtained in previous PET studies on saccadic eye movements (Fox et al., 1985a; Petit et al., 1993; Anderson et al., 1994; Lang et al., 1994). Electrophysiological studies on the monkey have initially described and defined these SEFs and have shown their role in the control of the saccade (Schlag and Schlag-Rey, 1987; Huerta and Kaas, 1990), especially during a memorized oculomotor task (Mann et al., 1988). Gaymard et al. (1990, 1993) studied patients suffering from a lesion of the left SMA and showed that the execution of memorized sequences of two or three saccades was severely affected, whichever the stimulated visual hemifield. Our results agree with these clinical studies that show the leading role of the SEF in the execution of prelearned saccades sequences. In addition, another sort of deficiency related to lesions of the SMA has been observed in the duplicating of the rhythm of a movement, primarily if the patients had to execute alternating movements with both hands (Halsband et al., 1993). These patients did not suffer from any deficiency of their skill or of their rhythm discrimination. In our study, the duplicating of a prelearned saccades sequence for 2 min creates a strong rhythmic element that could explain partly the stronger SEF activation during such an oculomotor task. In addition, the subjects were instructed to reproduce the prelearned sequence while respecting as much as possible the rhythm of the initial presentation of the visual targets. This rhythmic element is also present during the execution of voluntary saccades in a simpler form, because the requirement is for simple right to left sweeping movements without visual information processing (Petit et al., 1993; Lang et al,, 1994). We noticed particularly a stronger NrCBF increase in the SEF during the execution of prelearned saccades sequences than during the execution of self-paced saccades. In addition, the comparison between both oculomotor tasks (SEQ vs SAC) allowed us to localize a maximum peak value more rostrally than those observed in the comparisons between each oculomotor task and the resting control condition. Electro- 
physiological findings have provided sufficient evidence that two separate motor areas exist in the SMA traditionally defined as a single motor area corresponding to the medial part of Brodmann's area 6 (for review, see Tanji, 1994). The term of pre-SMA has been proposed for the rostral part of the SMA in which the monkey abundant cue and trigger signal-locked neuronal responses have been described, indicating that the pre-SMA has access to visual information more readily than the SMA (Matsuzaka et al., 1992; Shima and Tanji, 1994). In contrast, the caudal part of the SMA or the SMA proper is closely connected with the primary motor cortex and the spinal cord (Tanji, 1994). Using the PET technique, Deiber et al. (1991) investigated the question of which cortical areas were active during movement selection in humans. The rostral part of the SMA differed in activity depending on how the selection was made, whereas the caudal part was similarly active under different motor conditions (Deiber et al., 1991). Stephan et al. (1995) recently confirmed such a functional rostrocaudal distinction in the SMA, with the AC line serving as a border between the pre-SMA and the SMA. By analogy with the skelcton motor system, we propose the term of pre-SEF to describe the rostral part of the traditionally defined SEF involved specifically in the selection and control of prelearned saccadic eye movements, i.e., during the execution of saccades guided by visuospatial data that are used for remembering and reproducing the movement. In terms of both preparation and execution of movement, these observations also support an analogy between the SEF proper and the SMA proper.

\section{A general network of saccadic eye movements}

The repetition of prelearned saccades sequences as well as the execution of self-paced horizontal saccades, both in total darkness, led to the activation of a common set of cortical and subcortical areas that were described previously in either similar self-paced saccade studies (Petit et al., 1993; Lang et al., 1994) or other previous sensory-guided saccade studies (Fox et al., 1985a,b; Paus et al., 1993; Anderson et al., 1994; Nakashima et al., 1994; O'Driscoll et al., 1995, O'Sullivan et al., 1995; Sweeney et al., 1996). Thus, these findings endorsed the idea that a common network of cortical and subcortical regions is generally activated in the performance of saccadic eye movements. The three main components of the frontocingulate part of this network should be the FEF, the SEF, and the median part of the cingulate gyrus underlying the SEF. To this cortical network, one should add a consistent involvement of subcortical structures such as the lenticular nucleus and the thalamus, which would indicate that saccadic eye movements could be under the control of the motor gangliothalamocortical loop (Alexander et al., 1986). Finally, the cerebellar vermis should constitute the last structure involved, whatever the executed saccades.

Depending on the subject, either left- or right-hand-side insular activations also were found during both the prelearned sequences and the sclf-paced saccades. Because of its specific detection with the HMSD analysis, this insular activation could not be attributed to a partial volume effect of the nearby lenticular nucleus activations. Previous PET studies have described similar insular activations during the performance of saccades (Petit et al., 1993; Anderson et al., 1994) and during selective visual attention (Corbetta et al., 1991). Contralateral insula activation has also been reported during voluntary limb movements (Chollet et al., 1991; Colebatch et al., 1991). All of these features suggest that the insula might be a secondary motor area that is activated in paced stereotyped tasks.

Finally, specific comments concerning the location of the human FEF in the precentral gyrus should be added. No ambiguity exists concerning the accurate localization of FEF in the monkey since Ferrier's pioneering studies (Ferrier, 1875). An overview of the studies made on the monkey leads to the same anatomical definition: the rostral part of the arcuate sulcus (for review, see Goldberg and Segraves, 1989, 1990). This area, smaller than Brodmann's area 8 , corresponds precisely with areas $8 \mathrm{a}$ and 45 of Walker's map (Walker, 1940). Different saccade-related, fixationrelated, and more recently, pursuit-related neurons were characterized in the FEF of the monkey (Goldberg and Segraves, 1990; Gottlieb et al., 1994). Using functional brain imaging in humans, Petit et al. (1993) proposed recently that the FEFs are located in the precentral gyrus. By analogy with the definition of FEF in monkeys, only the precentral area previously had been found to be activated in humans during both saccade-related (Paus et al., 1993; Petit et al., 1993; Anderson et al., 1994; Lang et al., 1994; Nakashima et al., 1994; O'Sullivan et al., 1995; Paus et al., 1995; Sweeney et al., 1996) and fixation-related (Petit et al., 1995) tasks, thus confirming the location of such a functional area. In the present study, the NrCBF increase in the FEF during the execution of voluntary saccades and prelearned sequences of saccades was similar when compared with the resting control condition and showed that the activation of this region is not dependent on the type of requested saccadic movements. These two types of saccades, however, which activate the FEF in total darkness, reinforce the idea that all fully volitional saccades are preceded by FEF activation, as initially demonstrated in the monkey (Bruce and Goldberg, 1985).

\section{REFERENCES}

Alexander GE, Delong MR, Strick PL (1986) Parallel organization of functionally segregated circuits linking basal ganglia and cortex. Annu Kev Neurosci $9: 357-381$.

Andersen RA, Gnadt JW (1989) Posterior parietal cortex. In: The neurobiology of saccadic eye movements (Wurtz RH, Goldberg ME, eds), pp 315-335. Amsterdam: Elsevier.

Anderson TJ, Jenkins IH, Brooks DJ, Hawken MB, Frackowiak RSJ, Kennard C (1994) Cortical control of saccades and fixation in man: a PET study. Brain 117:1073-1084.

Balint R (1909) Seelenlähmung des "Schauens," optische Ataxie, räumliche Störung der Aufmerksamkeit. Monatsschr Psychiatr Neurol 25:51-81.

Barash S, Bracewell RM, Fogassi L, Gnadt JW, Andersen RA (1991) Saccade-related activity in the lateral intraparietal area. 1. Temporal properties: comparison with area 7a. J Neurophysiol 66:1095-1108.

Becker W, Fuchs AF (1969) Further properties of the human saccadic system: eye movements and correction saccades with and without visual fixation. Vision Res 9:1247-1257.

Becker W, Klein HM (1973) Accuracy of saccadic cye movements and maintenance of eccentric eye positions in the dark. Vision Res 13:1021-1034.

Berthoz A, Mazoyer B, Petit I, Orssaud C, Raynaud I, T7ourio N (1992) Bilateral parietal involvement in the execution of a sequence of memorized saccades in man. Soc Neurosci Abstr 18:214.

Bruce CJ, Goldberg ME (1985) Primate frontal eye fields. 1. Single neurons discharging before saccades. J Neurophysiol 53:603-635.

Chollet F, DiPiero V, Wise RJS, Brooks DJ, Dolan RJ, Frackowiak RSJ (1991) The functional anatomy of motor recovery after stroke in humans: a study with positron emission tomography. Ann Neurol 29:63-71.

Colebatch JG, Deiber MP, Passingham RE, Friston KJ, Frackowiak RSJ (1991) Regional cerebral blood flow during voluntary arm and hand movements in human subjects. J Neurophysiol 65:1392-1401.

Corbetta M, Miczin FM, Dobmeyer S, Shulman GL, Petersen SE (1991) Selective and divided attention during visual discriminations of shape, 
color, and speed: functional anatomy by positron emission tomography. J Neurosci 11:2383-2402.

Corbetta M, Miezin FM, Shulman GL, Petersen SE (1993) A PET study of visuospatial attention. J Neurosci 13:1202-1226.

Corbetta M, Shulman GL, Miezin FM, Petersen SE (1995) Superior parietal cortex activation during spatial attention shifts and visual feature conjunction. Science 270:802-805.

Courtney SM, Ungerleider LG, Keil K, Haxby JV (1996) Object and spatial visual working memory activate separate neural systems in human cortex. Cereb Cortex, in press.

Crivello F, Tzourio N, Poline JB, Woods R, Mazziotta JC, Mazoyer B (1995) Intersubject variability in functional neuroanatomy of silent verb generation: assessment by a new activation detection algorithm based on amplitude and size information. Neuroimage 2:253-263.

Deiber MP, Passingham RE, Colebatch JG, Friston KJ, Nixon PD, Frackowiak RSJ (1991) Cortical areas and the selection of movement: a study with positron emission tomography. Exp Brain Res 84:393-402.

Duhamel JR, Colby CL, Goldberg ME (1992) The updating of the representation of visual space in parietal cortex by intended eye movements. Science 255:90-92.

Eidelberg D, Galaburda AM (1984) Inferior parietal lobulc: divergent architectonic asymmetries in the human brain. Arch Neurol $41: 843-852$.

Ferrier D (1875) Experiments on the brain of monkeys. Proc R Soc I and [Biol] 165:433-488.

Fox PT, Fox JM, Raichle ME, Burde RM (1985a) The role of cerebral cortex in the generation of voluntary saccades: a positron emission tomographic study. J Neurophysiol 54:348-369.

Fox PT, Raichle ME, Thach WT (1985b) Functional mapping of the human cerebellum with positron emission tomography. Proc Natl Acad Sci USA 82:7462-7466

Friston KJ (1995) Statistical parametric mapping: ontology and current issues. J Cereb Blood Flow Metab 15:361-370.

Friston KJ, Frith CD, Liddle PF, Frackowiak RSJ (1991) Comparing functional (PET) images: the assessment of significant change. J Cereb Blood Flow Metab 11:690-699.

Friston KJ, Worsley KJ, Frackowiak RSJ, Mazziotta JC, Evans AC (1494) Assessing the significance of focal activations using their spatial extent. Hum Brain Map 1:210-220.

Fuster JM (1995) Memory in the cerebral cortex: an empirical approach to neural networks in the human and nonhuman primate. Cambridge: MIT.

Gaymard B, Pierrot-Deseilligny C, Rivaud S (1990) Impairment of sequences of memory-guided saccades after supplementary motor area lesions. Ann Neurol 28:622-626.

Gaymard B, Rivaud S, Pierrot-Deseilligny C (1993) Role of the left and right supplementary motor areas in memory-guided saccades sequences. Ann Neurol 34:404-406.

Ghatan PH, Hsieh JC, Wirsen-Meurling A, Wredling R, Eriksson L, Stone-Elander S, Levander S, Ingvar M (1995) Brain activation induced by the perceptual maze test: a PET study of cognitive performance. Neuroimage 2:112-124.

Gnadt JW, Andersen RA (1988) Memory related motor planning activity in posterior parietal cortex of macaque. Exp Brain Res 70:216-220.

Goldberg ME, Segraves MA (1989) The visual and frontal cortices. In: The neurobiology of saccadic eye movements (Wurtz RH, Goldberg ME, eds), pp 283-313. Amsterdam: Elsevier.

Goldberg ME, Segraves MA (1990) The role of the frontal eye field and its corticotectal projection in the generation of eye movements. In: Vision and the brain (Cohen B, Bodis-Wollner I, eds), pp 195-209. New York: Raven.

Gottlieb JP, McAvoy MG, Bruce CJ (1994) Neural responses related to smooth-pursuit eye movements and their correspondence with electrically clicitcd smooth cyc movements in the primate frontal cyc ficld. $J$ Neurophysiol 72:1634-1653.

Halsband U, Ito N, Tanji J, Freund HJ (1993) The role of premotor cortex and the supplementary motor area in the temporal control of movement in man. Brain 116:243-266.

Haxby JV, Grady CL, Horwitz B, Ungerleider LG, Mishkin M, Carson RE, Herscovitch P, Schapiro MB, Rapoport SI (1991) Dissociation of object and spatial visual processing pathways in human extrastriate cortex. Proc Natl Acad Sci USA 88:1621-1625.

Haxby JV, Horwitz B, Ungerleider LG, Maisog JM, Pietrini P, Grady CL (1994) The functional organization of human extrastriate cortex: a
PET-rCBF study of selective attention to faces and locations. J Neurosci $14: 6336-6353$.

Hecaen H, De Ajuriaguerra J (1954) Balint's syndrome (psychic paralysis of visual fixation) and its minor forms. Brain 77:373-400.

Holmes G (1938) The cerebral integration of the ocular movements. $\mathrm{Br}$ Med J 2:107-112.

Huerta MF, Kaas JH (1990) Supplementary eye field as defined by intracortical microstimulation: connections in macaques. J Comp Neurol 293:299-330

Israël I (1992) Memory-guided saccades: what is memorized? Exp Brain Res 90:221-224.

Israël I, André-Deshays C, Charade O, Berthoz A, Popov K, Lipshits M (1993) Gaze control in microgravity. 2. Sequences of saccades toward memorized visual targets. J Vestib Res 3:345-360.

Jonides J, Smith EE, Koeppe RA, Awh E, Minoshima S, Mintun MA (1993) Spatial working memory in humans as revealed by PET. Nature 363:623-625

Körner FH (1975) Non-visual control of human saccadic eye movements. In: Basic mechanisms of ocular motility and their clinical implications (Lennerstrand G, Bach-y-Rita P, eds), pp 565-569. Oxford: Pergamon.

Lang W, Petit L, Höllinger P, Pietrzyk U, Tzourio N, Mazoyer B. Berthoz A (1994) A positron emission tomography study of oculomotor imatgery. NeuroReport 5:921-1924.

Luria AR, Praudina-Vinarskaya EN, Yarbuss AL (196.3) Disorder of ocular movement in a case of similtanagnosia. Brain 86:219-228.

Mann SE, Thau R, Schiller PH (1988) Conditional task-related responses in monkey dorsomedial frontal cortex. Exp Brain Res $69: 460-468$.

Matsuzaka Y, Aizawa H, Tanji J (1992) A motor area rostral to the supplementary motor area (presupplementary motor area) in the monkey: neuronal activity during a learned motor task. J Neurophysiol 68:653-662.

Mazoyer B, Trebossen R, Deutch R, Cascy M, Blohm K (1991) Physical characteristics of the ECAT 953B/31: a new high resolution brain positron tomograph. IEEE Trans Med Imag 10:499-504.

Mazoyer BM, Tzourio N, Frak V, Syrota A, Murayama N, Levrier O, Salamon G, Dehaene S, Cohen L, Mehler J (1993) The cortical representation of speech. J Cogn Neurosci 5:467-479.

Mellet E, Crivello F, Tzourio N, Joliot M, Petit L, Laurier L, Denis M, Mazoyer B (1995) Construction of mental images based on description: functional neuroanatomy with PET. Hum Brain Map [Suppl] $1: 273$.

Mesulam MM (1981) A cortical network for directed attention and unilateral neglect. Ann Neurol 10:309-325.

Mesulam MM (1990) Large-scale neurocognitive networks and distributed processing for attention, language, and memory. Ann Neurol 28:597-613.

Miezin FM, Corbetta M, Webb GL, Raichle ME, Petersen SE (1992) PET activations for visual and memory saccades. Soc Neurosci Abstr 18:689-690.

Mishkin M, Ungerleider LG, Macko KA (1983) Object vision and spatial vision: two cortical pathways. Trends Neurosci 6:414-417.

Nakashima Y, Momose T, Sano I, Katayama S, Nakajima T, Niwa S-I. Matsushita M (1994) Cortical control of saccade in normal and schizophrenic subjects: a PET study using a task-evoked rCBF paradigm. Schizophr Res 12:259-264.

O'Driscoll GA, Alpert NM, Matthysse SW, Levy DL, Rauch SL, Holzman PS (1995) Functional neuroanatomy of antisaccade eye movements investigated with positron emission tomography. Proc Natl Acad Sci USA 92:925-929.

O'Sullivan EP, Jenkins IH, Henderson I., Kennard C, Brooks DJ (1995) The functional anatomy of remembered saccades: a PET study. NeuroReport 6:2141-2144.

Passingham RE (1988) Prcmotor cortcx and preparation for movement. Exp Brain Res 70:590-596.

Paus T, Petrides M, Evans AC, Meyer E (1993) Role of the human anterior cingulate cortex in the control of oculomotor, manual, and speech responses: a positron emission tomography study. J Neurophysiol 70:453-469.

Paus T, Marrett S, Worsley KJ, Evans AC (1995) Extraretinal modulation of cerebral blood flow in the human visual cortex: implications for saccadic suppression. J Neurophysiol 74:2179-2183.

Petit L, Orssaud C, Tzourio N, Salamon G, Mazoyer B, Berthoz A (1993) PET study of voluntary saccadic eye movements in humans: basal 
ganglia-thalamocortical system and cingulate cortex involvement. J Neurophysiol 69:1009-1017.

Petit L, Tzourio N, Orssaud C, Pietrzyk U, Berthoz A, Mazoyer B (1995) Functional neuroanatomy of the human visual fixation system. Eur $\mathbf{J}$ Neurosci 7:169-174.

Pierrot-Deseilligny C, Gautier JC, Loron P (1988) Acquired ocular motor apraxia due to bilateral frontoparietal infarcts. Ann Neurol 23:199-202.

Pierrot-Deseilligny C, Rivaud S, Gaymard B (1991a) Cortical control of reflexive visually-guided saccades in man. Brain 114:1473-1485.

Pierrot-Deseilligny C, Rivaud S, Gaymard B, Agid Y (1991b) Cortical control of memory-guided saccades in man. Exp Brain Res 83:607-617.

Pièrrot-Deseilligny C, Rivaud S, Gaymard B, Müri RM, Vermersch AI (1995) Cortical control of saccades. Ann Neurol 37:557-567.

Pierrot-Deseilligny C, Rivaud S, Penet C, Rigolet MH (1987) Latencies of visually guided saccades in unilateral hemispheric cerebral lesions. Ann Neurol 21:138-148.

Poline JB, Mazoyer BM (1994) Analysis of individual brain activation maps using hierarchical description and multiscale detection. IEEE Trans Med Imaging 13:702-710.

Rondot P, De Recondo J (1974) Ataxie optique: trouble de la coordination visuo-motrice. Brain Res 71:367-375.

Schlag J, Schlag-Rey M (1987) Evidence for a supplementary eye field. J Neurophysiol 57:179-200.

Shibutani H, Sakata H, Hyvarinen J (1984) Saccade and blinking evoked by microstimulation of the posterior parietal association cortex of the monkey. Exp Brain Res 55:1-8.
Shima K, Tanji J (1994) Neuronal activity in the supplementary and pre-supplementary motor area in relation to sequential performance of multiple movements. Soc Neurosci Abstr 24:986.

Stephan KM, Fink GR, Passingham RE, Silbersweig D, CeballosBaumann AO, Frith CD, Frackowiak RSJ (1995) Functional anatomy of mental representation of upper extremity movements in healthy subjects. J Neurophysiol 73:373-386.

Sweeney JA, Mintun MA, Kwee S, Wiseman MB, Brown DL, Rosenberg DR, Carl JR (1996) Positron emission tomography study of voluntary saccadic eye movements and spatial working memory. J Neurophysiol 75:454-468.

Talairach J, Tournoux P (1988) Co-planar stereotaxic atlas of the human brain. New York: Thieme Medical Publishers.

Tanji J (1994) The supplementary motor area in the cerebral cortex. Neurosei Res 19:251-268.

Ungerleider LG, Haxby JV (1994) "What" and "where" in the human brain. Curr Opin Neurobiol 4:157-165.

Walker AEA (1940) A cytoarchitectural study of the prefrontal area of the macaque monkey. J Comp Neurol 73:59-86.

Woods RP, Cherry SR, Mazziotta JC (1992) Rapid automated algorithm for aligning and reslicing PET images. J Comput Assist Tomogr 16:620-633.

Wonds RP, Mazziotta JC, Cherry SR (1993) MRI-PET registration with automated algorithm. J Comput Assist Tomogr 17:536-546.

Zingale CM, Kowler E (1987) Planning sequences of saccades. Vision Res 27:1327-1341. 